\title{
Advances in managing breast cancer: a clinical update
}

\author{
Ayca Gucalp ${ }^{1,2}$, Gaorav P. Gupta ${ }^{3}$, Melissa L. Pilewskie ${ }^{4}$, Elizabeth J. Sutton ${ }^{5}$ \\ and Larry Norton ${ }^{1,2 *}$
}

\author{
Addresses: ${ }^{1}$ Breast Cancer Medicine Service, Department of Medicine, Memorial Sloan Kettering Cancer Center, New York, NY10065, USA; \\ ${ }^{2}$ Department of Medicine, Weill Cornell Medical College, New York, NY 10065, USA; ${ }^{3}$ Department of Radiation Oncology, Memorial Sloan \\ Kettering Cancer Center, New York, NY 10065, USA; ${ }^{4}$ Breast Service, Department of Surgery, Memorial Sloan Kettering Cancer Center, New York, \\ NY 10065, USA; ${ }^{5}$ Breast Imaging Service, Department of Radiology, Memorial Sloan Kettering Cancer Center, New York, NY 10065, USA \\ * Corresponding author: Larry Norton (nortonl@mskcc.org) \\ FI000Prime Reports 2014, 6:66 (doi:10.12703/P6-66) \\ All FI000Prime Reports articles are distributed under the terms of the Creative Commons Attribution-Non Commercial License \\ (http://creativecommons.org/licenses/by-nc/3.0/legalcode), which permits non-commercial use, distribution, and reproduction in any medium, \\ provided the original work is properly cited. \\ The electronic version of this article is the complete one and can be found at: http://fl000.com/prime/reports/m/6/66
}

\begin{abstract}
Although substantial progress has been made in the screening and management of breast cancer, globally it remains the most common cause of cancer and cancer death in women. While breast cancer is potentially curable when detected at an early stage, it remains incurable in the metastatic setting. Thus, given its high prevalence, improved prevention and treatment of metastases remains a clinically meaningful unmet need. We review here the advances made in the last several years in the screening and treatment of breast cancer and explore how our increased insight into the underlying biology of breast cancer has influenced our efforts to individualize patient care.
\end{abstract}

\section{Introduction}

Breast cancer remains a significant public health challenge both in the United States and worldwide. While breast cancer is potentially curable when detected at an early stage, it remains incurable in the metastatic setting. Hence, there has been a major effort to detect breast cancer early, optimize the management of early-stage disease to prevent or delay distant recurrence, and improve the treatment of metastases. Breast cancer heterogeneity is a well-recognized phenomenon. Each subtype is characterized by varied risk factors, clinicopathologic and molecular features, responses to therapy, patterns of recurrence, and clinical outcomes. As our understanding of the underlying biologic diversity of breast cancer has evolved, this knowledge has prompted investigators and clinicians alike to abandon a "one-size-fits-all" model of management. This review highlights the advances made in the screening and treatment of breast cancer and explores how our increased insight into the underlying biology of breast cancer has influenced our diagnostic and therapeutic approach in the era of precision medicine.

\section{Radiology: advances in screening}

Screening mammography for the early detection of breast cancer in women went into widespread use in the 1970s and 1980s, and randomized controlled trials (RCTs) have shown a significant reduction in mortality [1]. While supplementary screening techniques and computer-aided diagnosis (CAD) are being used more widely, equally effective digital or screen-film 2D mammography remains the mainstay of breast cancer screening, detecting 2-4 cancers per 1000 average-risk women screened $[2,3]$. Screening recommendations vary by institution, professional organization, and country. However, current guidelines from the American College of Radiology (ACR), American Society of Clinical Oncology (ASCO), Society of Breast Imaging (SBI) and United States Preventive Services Task Force (USPSTF) all recommend yearly mammographic screening beginning at age 40 for the general population. Furthermore, the Breast Imaging-Reporting and Data System (BIRADS) optimizes our standardized lexicon terminology and assessment, facilitating global communication. 
Digital breast tomosynthesis (DBT) is a new 3D method of screening approved by the United States Food and Drug Administration (FDA) that captures images of the compressed breast from multiple angles and combines them to generate a 3D rendering of the breast. DBT can depict cancers not visible on the standard mammogram, improving sensitivity and specificity in all breasts while also decreasing recall rates. Furthermore, it is associated with only a minimal increase in low dose radiation and no significant screening time difference, when compared to 2D mammography. DBT is rapidly being incorporated into clinical practice, and the future may see it completely replace 2D mammography [4].

A current topic of interest for many (including individual women, radiologists and the government) is breast density. Breast density refers to the proportions of fat and fibroglandular tissue in a breast, which varies between women and over time. Breast tissue can be categorized as: predominantly fatty, scattered fibroglandular, heterogeneous or extremely dense. Increased breast density (heterogeneous or extremely dense) is an independent risk factor for breast cancer and can decrease sensitivity of cancer detection on mammogram due to the superimposition of fibroglandular tissue [5]. Approximately half of all states in the US have either drafted or enacted breast density notification legislature requiring a radiologist to notify patients if they are found to have dense breasts. In response, utilization of supplemental screening techniques (including screening bilateral breast ultrasound or magnetic resonance imaging [MRI]) in women with dense breasts has increased [6].

The addition of screening ultrasound to mammography has been shown to detect an additional 3-4 cancers per 1000 high-risk women screened [7]. Screening ultrasound should supplement but not replace a mammogram. It is sensitive, painless and does not use radiation. Breast sonographers are trained to minimize interperformer variability. Ultrasound elastography is an adjunct tool to gray scale and color Doppler, which dynamically assesses the mechanical stiffness of tissue, increasing the specificity for characterizing masses [8]. Three-dimensional automated breast ultrasound has been developed to eliminate inter-performer variability and also to optimize workflow, since the exams are time consuming. CAD for 3D automated breast ultrasound is also in development [9]. Contrast enhanced ultrasound is currently being investigated to potentially assist in increasing sensitivity and specificity [10].

Screening recommendations for women at high-risk (e.g. $>20 \%$ lifetime risk of breast cancer), determined by risk assessment models that are predominantly based on family history (e.g. Tyrer-Cuzick, Claus, BRCAPRO, and BOADICEA), include a yearly screening mammogram and bilateral breast MRI. The stratification of risk continues to evolve as more emphasis is placed on patient characteristics, such as age and co-morbidities. Studies are also currently evaluating the role of supplementary screening in intermediate-risk women [11]. MRI computer-aided detection is being investigated as a possible means for improving detection sensitivity and diagnostic accuracy [12]. Due to the high cost, MRI is less widely used as a supplemental screening tool in the general population. However, shorter MRI screening protocols are being developed, which cost approximately the same as a screening ultrasound. These protocols will combine both short temporal resolution and high-spatial resolution sequences.

The evolution of breast screening will continue to parallel technologic and scientific advancement. The heterogeneous nature of breast cancer defined by different genotypes and phenotypes has fueled the field of radiogenomics. Radiogenomics involves correlating radiologic imaging with genetic information. In parallel with the goal of optimizing personalized medicine, this field will further inform the development of risk-adjusted screening.

\section{Surgery: advances in surgery}

Sentinel lymph node biopsy (SLNB) has revolutionized the surgical management for clinically node-negative breast cancer patients. Studies performed in the late 1990s and early 2000s established the SLNB procedure alone as standard axillary staging for pathologically node-negative disease $[13,14]$, and reported rates of axillary recurrence of $<1 \%$ [15], substantially lower than the percentage of disease left in situ given the 7\% SLNB false-negative rate [16]. The knowledge that not all microscopic axillary disease becomes clinically apparent, and that rates of regional recurrence have been declining with increased utilization of adjuvant therapy, has led to the investigation of SLNB for the management of node-positive patients as well.

Two RCTs compared SLNB alone to completion axillary lymph node dissection (ALND) for patients with micrometastatic axillary sentinel lymph node (SLN) disease, defined as $<2 \mathrm{~mm}$ of tumor burden $[17,18]$. The International Breast Cancer Study Group (IBCSG) 23-01 trial enrolled women with a primary breast tumor $\leq 5 \mathrm{~cm}$ from 27 institutions, from 2001-2010. At a median follow-up of 5 years, the axillary recurrence rate was $<1 \%$ in both surgical arms. Disease-free survival (DFS) and overall survival (OS) were also similar among the SLNB and ALND groups (DFS $88 \%$ vs $84 \%$, respectively, log-rank $P=0.16$; OS $98 \%$ vs $98 \%$, respectively, log-rank $P=0.73$ ) [17]. Similarly, a multicenter RCT from Spain randomized 
233 women with a tumor $<3.5 \mathrm{~cm}$ and an SLN with micrometastatic disease to SLNB alone or ALND. At a median follow-up of 5.2 years, only four cases of any disease recurrence were reported. There were two axillary recurrences in the SLNB group and one axillary soft tissue recurrence in the ALND group. DFS and OS were similar between the surgical arms (log-rank, $P=0.33$ ) [18].

ALND specimens and SLNs are examined differently by pathologists. In the earlier trials, SLNs were evaluated with serial sectioning followed by pathological evaluation with both hematoxylin and eosin (H\&E) staining and cytokeratin immunohistochemistry, which resulted in an increased detection of micrometastatic axillary disease [19]. ACOSOG Z0010 evaluated the prevalence and significance of immunohistochemistry-detected micrometastasis among patients with T1-T2 clinically node-negative disease. All women underwent lumpectomy and SLNB with pathologic evaluation by $\mathrm{H} \& \mathrm{E}$ staining alone. Immunohistochemistry was then performed on H\&Enegative SLNs and $10.5 \%$ were found to contain immunohistochemistry-detected occult metastases. At a median follow-up of 6.3 years, there was no significant difference in recurrence or death between women with or without immunohistochemistry-detected disease (5-year DFS, 92\% immunohistochemistry-negative SLN vs $90 \%$ immunohistochemistry-positive SLN, $P=0.82$ ) [20]. NSABP B32 also examined the prognostic significance of immunohistochemistry-positive SLNs and, at 10 years of follow-up, reported no significant difference in overall survival between patients with immunohistochemistrypositive or immunohistochemistry-negative disease [21]. Because immunohistochemistry-detected micrometastatic disease does not impact recurrence or overall survival, the use of routine immunohistochemistry for SLN evaluation is not warranted.

These trials established the safety of SLNB alone for micrometastatic disease, and led to guideline changes omitting the routine use of immunohistochemistry for SLN evaluation [22]. Given that the definition of micrometastatic disease is an arbitrary cutoff of $2 \mathrm{~mm}$, studies next investigated the use of SLNB for women with SLN macrometastatic ( $>2 \mathrm{~mm}$ ) disease burden. ACOSOG Z0011 randomized women with clinical T1-2N0M0 breast cancer who were found to have 1-2 positive SLNs detected by $\mathrm{H} \& \mathrm{E}$ alone to SLNB or to completion ALND. All women were treated with lumpectomy and whole breast radiation therapy, and 97\% received systemic therapy. Of the ALND group, $27 \%$ had additional positive lymph nodes, so it is assumed that a similar percentage in the SLNB group had residual diseased tissue. At a median follow-up of 6.3 years, regional recurrences occurred in $<1 \%$ of each group $(0.9 \%$ SLNB vs $0.5 \%$ ALND, $P=0.11)$
[23]. ACOSOG Z0011 was practice changing. In this select patient population treated with multimodality therapy, the morbidity of ALND can safely be avoided by staging the axilla with SLNB alone.

In addition to axillary management, recent advances regarding margins in breast-conserving surgery have been reported. Controversy has existed amongst surgeons and radiation oncologists regarding the adequate negative margin width in a lumpectomy specimen, and approximately $25 \%$ of all patients undergoing breast-conserving surgery undergo re-excision for close or positive margins [24,25]. A multidisciplinary consensus panel [26] recently met and reviewed an updated meta-analysis of margin width and local recurrence for women undergoing lumpectomy with whole breast radiotherapy for invasive carcinoma, reporting on over 28,000 patients [27]. Positive margins, defined as "ink on tumor", are associated with an increase in local recurrence, and therefore reexcision is appropriate. However, margins more widely negative than "no ink on tumor" are not associated with a significant reduction in local recurrence, and routine reexcision to obtain more widely negative margins is not recommended. Having a unified definition of negative margins as "no ink on tumor" has the potential to reduce unnecessary re-excisions, which will have significant impact on cosmesis and healthcare costs.

\section{Radiation oncology: advances in radiotherapy}

Radiation therapy is an effective treatment for microscopic residual disease after the surgical management of breast cancer, and thereby reduces the incidence of locoregional failure. Meta-analyses have established that the improvements in local and regional control that result from radiotherapy are also associated with reductions in distant metastases and breast cancer-specific mortality [28]. The utilization of adjuvant radiotherapy has enabled breastconserving therapy to become the standard approach for most women who present with early-stage breast cancer $[29,30]$. Additionally, higher-risk patients in the postmastectomy setting also benefit from radiotherapy to the chest wall and regional lymph nodes, with significant reductions observed in local-regional failure, distant metastases, and increased OS [28,31-33].

The excellent local control rates of luminal A breast cancer after breast-conserving therapy has led to the question of whether adjuvant radiotherapy may be omitted in certain low-risk breast cancer patient subsets [34]. There are 5 RCTs that have evaluated the need for postoperative radiotherapy in early stage, estrogen receptor positive (ER+) breast cancer, undergoing breast-conserving surgery in the setting of adjuvant hormonal therapy [35-39]. All of these studies demonstrated an effect of radiotherapy in 
preventing local recurrence that was statistically superior to the local control benefit of hormonal therapy alone. However, the absolute reduction in local recurrence by radiotherapy, particularly among elderly patients with ER+ breast cancer, was significantly less than had been previously observed for unselected breast cancer patients. For this reason, the routine use of adjuvant radiotherapy for older women with cT1-2N0 ER+ breast cancer who undergo breast-conserving surgery and adjuvant hormonal therapy is no longer considered a standard of care.

A potential alternative to conventional whole-breast radiotherapy in low-risk, early-stage breast cancer patients that is currently under investigation is accelerated partial breast irradiation (APBI), which has the additional advantage of being delivered over a shorter time interval. There are large, prospective randomized clinical trials (NSABP B-39/RTOG 0413 and the Canadian RAPID) that are currently ongoing. Results are eagerly awaited for both toxicity and local control outcomes relative to whole breast irradiation, which should establish the appropriate indications for APBI utilization. The interim report of increased rates of adverse cosmesis and late radiation toxicity with 3D-CRT APBI in the RAPID trial [40] is a reason for caution in using this approach outside of a clinical trial.

Radiotherapy is increasingly recognized as an equally effective and less morbid alternative to ALND in CT1-2NO patients who have 1-2 positive SLNs identified at the time of surgery. ACOSOG Z0011 was the first trial to demonstrate that an ALND was not required in such patients, and adjuvant treatment with tangential field whole breast radiotherapy (which frequently includes the inferior axillary lymph nodes) results in excellent regional control [41]. The EORTC AMAROS trial also investigated CT1-2N0 patients with a positive SLNB, with randomization either to ALND or axillary radiotherapy [42]. This trial was notable for including patients who underwent mastectomy as well as those who underwent breast-conserving surgery. The interim results of this trial have revealed very low 5-year axillary recurrence rates in both treatment arms, with significantly less lymphedema in the axillary radiotherapy arm relative to the ALND arm (5-year incidence $14 \%$ vs $28 \%$, respectively) [43].

Neoadjuvant chemotherapy is an established approach for the management of locally advanced breast cancer that is either unresectable or potentially cytoreduced to enable breast-conserving surgery. However, there is also a growing appreciation that the pathological response to neoadjuvant chemotherapy has prognostic significance for the likelihood of distant metastases and OS [44]. Retrospective analysis of the NSABP B18 and B27 trials also identified a correlation between pathological complete response to neoadjuvant chemotherapy and reduced likelihood of both local and regional failure [45]. Whether a patient with locally advanced breast cancer who achieves a pathological complete response to neoadjuvant chemotherapy can forgo post-mastectomy radiation therapy (PMRT) remains an open and unanswered question. Retrospective data suggests that withholding PMRT in such patients may be associated with increased rates of local-regional failure [46], although these studies may be highly subject to selection bias. Prospective randomized trials to address the utility of PMRT in the neoadjuvant chemotherapy setting are sorely needed, and will hopefully begin accruing patients in the near future.

\section{Medical oncology: advances in the medical management of metastatic breast cancer}

Outcomes for patients diagnosed with metastatic breast cancer continue to improve, as our understanding of the drivers of cancer growth continue to evolve hand in hand with the development of novel targeted therapies. Nowhere is this advancement more evident than in the treatment of patients with human epidermal growth factor receptor 2 (HER2)-positive breast cancer. In the last two years, the FDA has approved two new agents for the management of this subtype of breast cancer.

Pertuzumab is a humanized monoclonal antibody that binds to HER2 at a distinct epitope from trastuzumab on the extracellular domain, and inhibits the heterodimerization of HER2 and other HER-family receptors, preventing downstream signaling through the PI3K pathway and consequent tumor growth. The CLEOPATRA trial randomized 808 patients with HER2-positive metastatic breast cancer to receive trastuzumab and docetaxel in combination with either placebo (control) or pertuzumab. Based on improvement in median progression-free survival (18.5 vs 12.4 months; hazard ratio $(\mathrm{HR})=0.62 ; 95 \%$ confidence interval (CI), 0.51 to $0.75 ; P<0.001$ ) and overall survival $(\mathrm{HR}=0.66 ; 95 \% \mathrm{CI}, 0.52$ to $0.84 ; P=$ 0.0008 ) between the group receiving pertuzumab as compared to the control group, this drug was approved in June 2012 as first-line treatment for HER2+ metastatic breast cancer. This agent also recently (September 2013) became the first drug approved for the neoadjuvant treatment of breast cancer under the FDA's accelerated approval program. Confirmatory results from additional clinical trials will be needed to maintain this approval [47].

Ado-trastuzumab emtansine (TDM-1) is a novel antibody-drug conjugate that links the monoclonal antibody trastuzumab to the cytotoxic agent DM-1, a derivative of maytansine with microtubule inhibitory properties. Between February 2009 and October 2011 the EMILIA 
trial, a large multicenter phase III trial, randomized 991 patients with HER2+ locally advanced or metastatic breast cancer to receive either the combination of capecitabine $1000 \mathrm{mg} / \mathrm{m}^{2}$ oral twice daily (days 1-14) and lapatinib $1250 \mathrm{mg}$ oral daily or TDM-1 $3.6 \mathrm{mg} / \mathrm{m}^{2}$ every 21 days. Treatment with TDM-1, as compared to lapatinib and capecitabine, resulted in a statistically significantly improvement in both median progressionfree survival ( 9.6 vs 6.4 months; $\mathrm{HR}=0.65 ; 95 \% \mathrm{CI}, 0.55$ to $0.77 ; P<0.001)$ and $\mathrm{OS}(30.9$ vs 25.1 months; $\mathrm{HR}=$ $0.68 ; 95 \%$ CI, 0.55 to $0.85 ; P<0.001$ ) [48]. TMD-1 was well-tolerated, with a toxicity profile which differed from that commonly reported with a combination of lapatinib plus capecitabine (primarily diarrhea, nausea, vomiting and palmar-plantar erythrodysesthesia). Based on this trial, this agent was FDA approved in February 2013 for the treatment of patients with metastatic HER2-positive breast cancer who previously received treatment with a taxane and/or trastuzumab in the metastatic setting, or whose disease recurred during or within six months of completing their adjuvant therapy [48].

Unfortunately some patients will develop disease recurrence despite adjuvant therapy, and many patients with metastatic disease do not respond to therapy, or develop refractory disease. Endocrine therapy is an integral part of both adjuvant and metastatic management of hormone receptor-positive breast cancer. The activation of the mammalian target of rapamycin (mTOR) signaling pathway has been associated with the development of resistance to endocrine therapy in patients with ER+ breast cancer. Based on this finding, it was hypothesized that the addition of everolimus, an mTOR inhibitor to exemestane (an aromatase inhibitor), may overcome resistance to this fundamental therapy. BOLERO-2, a multi-institutional randomized phase III trial, randomly assigned 724 patients in a 2:1 ratio to receive either the combination of everolimus and exemestane or exemestane and placebo. The combination of everolimus and exemestane improved median progression-free survival, in comparison to single agent exemestane, when assessed by both local investigators ( 6.9 vs 2.8 months; $H R=$ $0.43 ; P<0.001)$, and centrally (10.6 vs 4.1 months; HR = $0.36 ; P<0.001)$. This trial supports the use of this regimen to extend the benefit of endocrine therapy at relapse or disease progression [49]. Several additional combination therapies targeting cellular signaling pathways, associated with breast cancer progression (e.g. the PI3K/AKT survival pathway) and the development of resistance, are currently being investigated.

\section{Conclusion}

As screening and the surgical and medical management of breast cancer continue to evolve, so too will the role for radiotherapy. Novel molecular markers of biological behavior will be identified and validated, and there may be greater opportunities for risk-adaptive management. Furthermore, as clinical outcomes for breast cancer patients continue to improve, there is a growing appreciation that minimizing the long-term morbidities of therapy - such as cardiac toxicity, pneumonitis, fibrosis, lymphedema, and the risk of secondary malignancy - are also important and clinically relevant goals. Novel technologies and medical interventions that reduce the risk of such toxicities must be rigorously evaluated to determine the best way to improve clinical outcomes for breast cancer patients.

\section{Abbreviations}

ALND, axillary lymph node dissection; APBI, accelerated partial breast irradiation; CAD, computer-aided diagnosis; CI, confidence interval; DBT, digital breast tomosynthesis; DFS, disease-free survival; ER+, estrogen receptor positive; FDA, US Food and Drug Administration; H\&E, hematoxylin and eosin; HER, human epidermal growth factor receptor; HR, hazard ratio; MRI, magnetic resonance imagining; mTOR, mammalian target of rapamycin; OS, overall survival; PMRT, postmastectomy radiation therapy; RCT, randomized controlled trial; SLN, sentinel lymph node; SNLB, sentinel lymph node biopsy; TDM-1, ado-trastuzumab emtansine.

\section{Disclosures}

The authors declare that they have no disclosures.

\section{References}

I. Smith RA, Duffy SW, Gabe R, Tabar L, Yen AM, Chen TH: The randomized trials of breast cancer screening: what have we learned? Radiol Clin North Am 2004, 42:793-806.

2. Pisano ED, Gatsonis C, Hendrick E, Yaffe M, Baum JK, Acharyya S, Conant EF, Fajardo LL, Bassett L, D'Orsi C, Jong R, Rebner M; Digital Mammographic Imaging Screening Trial (DMIST) Investigators Group: Diagnostic performance of digital versus film mammography for breast-cancer screening. $N$ Engl J Med 2005, 353:I773-83.

FlOOOPrime RECOMMENDED

3. The Breast Cancer Surveillance Consortium: Cancer Rate (per I,000 examinations) and Cancer Detection Rate (per I,000 examinations) for I,838,372 Screening Mammography Examinations from 2004 to 2008 by Age - based on BCSC data through 2009. National Cancer Institute (NCI); 20I4. [http://breastscreening.cancer. gov/data/performance/screening/2009/rate_age.htm]l

4. Kopans DB: Digital breast tomosynthesis from concept to clinical care. Am J Roentgenol 2014, 202:299-308.

\section{FlOOOPrime}

5. Saftlas AF, Hoover RN, Brinton LA, Szklo M, Olson DR, Salane M, Wolfe JN: Mammographic densities and risk of breast cancer. Cancer 1991, 67:2833-8.

6. Hooley RJ, Greenberg KL, Stackhouse RM, Geisel JL, Butler RS, Philpotts LE: Screening US in patients with mammographically 
dense breasts: initial experience with Connecticut Public Act 09-41. Radiology 2012, 265:59-69.

\section{FIOOOPrime
RECOMMENDED}

7. Berg WA, Zhang Z, Lehrer D, Jong RA, Pisano ED, Barr RG, BöhmVélez M, Mahoney MC, Evans WP 3rd, Larsen LH, Morton MJ, Mendelson EB, Farria DM, Cormack JB, Marques HS, Adams A, Yeh NM, Gabrielli G; ACRIN 6666 Investigators: Detection of breast cancer with addition of annual screening ultrasound or a single screening MRI to mammography in women with elevated breast cancer risk. JAMA 2012, 307:1394-404.

\section{FlOOOPrime} RECOMMENDED

8. Berg WA, Cosgrove DO, Doré CJ, Schäfer FK, Svensson WE, Hooley RJ, Ohlinger R, Mendelson EB, Balu-Maestro C, Locatelli M, Tourasse C, Cavanaugh BC, Juhan V, Stavros AT, Tardivon A, Gay J, Henry JP, Cohen-Bacrie C; BEI Investigators: Shear-wave elastography improves the specificity of breast US: the BEI multinational study of 939 masses. Radiology 20I2, 262:435-49.

9. Padilla F, Roubidoux MA, Paramagul C, Sinha SP, Goodsitt MM, Le Carpentier GL, Chan HP, Hadjiiski LM, Fowlkes JB, Joe AD, Klein KA, Nees AV, Noroozian M, Patterson SK, Pinsky RW, Hooi FM, Carson PL: Breast mass characterization using 3-dimensional automated ultrasound as an adjunct to digital breast tomosynthesis: a pilot study. J Ultrasound Med 2013, 32:93-104.

10. Hu Q, Wang XY, Zhu SY, Kang LK, Xiao YJ, Zheng HY: Metaanalysis of contrast-enhanced ultrasound for the differentiation of benign and malignant breast lesions. Acta Radiol 2014. [Epub ahead of print]

II. Jochelson MS, Morris EA: An imaging approach to high-risk screening for breast cancer. Semin Roentgenol 201 I, 46:68-75.

12. Lehman CD, Blume JD, DeMartini WB, Hylton NM, Herman B, Schnall MD: Accuracy and interpretation time of computeraided detection among novice and experienced breast MRI readers. Am J Roentgenol 2013, 200:W683-9.

13. Veronesi U, Paganelli G, Viale G, Luini A, Zurrida S, Galimberti V, Intra M, Veronesi P, Maisonneuve P, Gatti G, Mazzarol G, De Cicco C, Manfredi G, Fernández JR: Sentinel-lymph-node biopsy as a staging procedure in breast cancer: update of a randomised controlled study. Lancet Oncol 2006, 7:983-90.

14. Krag DN, Anderson SJ, Julian TB, Brown AM, Harlow SP, Costantino IP, Ashikaga T, Weaver DL, Mamounas EP, Jalovec LM, Frazier TG, Noyes RD, Robidoux A, Scarth HM, Wolmark N: Sentinel-lymph-node resection compared with conventional axillary-lymph-node dissection in clinically node-negative patients with breast cancer: overall survival findings from the NSABP B-32 randomised phase 3 trial. Lancet Oncol 2010, I I:927-33.

15. van der Ploeg IM, Nieweg OE, van Rijk MC, Valdés Olmos RA, Kroon BB: Axillary recurrence after a tumour-negative sentinel node biopsy in breast cancer patients: A systematic review and meta-analysis of the literature. Eur J Surg Oncol 2008, 34:1277-84.

\section{FlOOOPrime \\ RECOMMENDED}

16. Kim T, Giuliano AE, Lyman GH: Lymphatic mapping and sentinel lymph node biopsy in early-stage breast carcinoma: a metaanalysis. Cancer 2006, 106:4-16.

\section{FIOOOPrime}

17. Galimberti V, Cole BF, Zurrida S, Viale G, Luini A, Veronesi P, Baratella P, Chifu C, Sargenti M, Intra M, Gentilini O, Mastropasqua MG, Mazzarol G, Massarut S, Garbay JR, Zgajnar J, Galatius H, Recalcati A, Littlejohn D, Bamert M, Colleoni M, Price KN, Regan MM, Goldhirsch A, Coates AS, Gelber RD, Veronesi U; International Breast Cancer Study Group Trial 23-0I investigators: Axillary dissection versus no axillary dissection in patients with sentinel-node micrometastases (IBCSG 23-0I): a phase 3 randomised controlled trial. Lancet Oncol 2013, 14:297-305.

FlOOOPrime

18. Sola M, Alberro JA, Fraile M, Santesteban P, Ramos M, Fabregas R, Moral A, Ballester B, Vidal S: Complete axillary lymph node dissection versus clinical follow-up in breast cancer patients with sentinel node micrometastasis: final results from the multicenter clinical trial AATRM 048/13/2000. Ann Surg Oncol 2013, 20:120-7.

\section{FlOOOPrime}

\section{RECOMMENDED}

19. Giuliano AE, Dale PS, Turner RR, Morton DL, Evans SW, Krasne DL: Improved axillary staging of breast cancer with sentine lymphadenectomy. Ann Surg 1995, 222:394-9; discussion 399-40I.

20. Giuliano AE, Hawes D, Ballman KV, Whitworth PW, Blumencranz PW, Reintgen DS, Morrow M, Leitch AM, Hunt KK, McCall LM, Abati A, Cote R: Association of occult metastases in sentinel lymph nodes and bone marrow with survival among women with early-stage invasive breast cancer. JAMA 201 I, 306:385-93.

\section{FIOOOPRIM
RECOMMENDED}

21. Julian TB, Anderson SJ, Krag DN, Harlow SP, Costantino JP, Ashikaga T, Weaver DL, Mamounas EP, Wolmark N: I O-yr follow-up results of NSABP B-32, a randomized phase III clinical trial to compare sentinel node resection (SNR) to conventional axillary dissection (AD) in clinically node-negative breast cancer patients [abstract]. Presented at the Annual Meeting of the American Society of Clincal Oncology: 31 May-4 June 2013; Chicago,

22. Wen PY, Yung WK, Lamborn KR, Dahia PL, Wang Y, Peng B, Abrey LE, Raizer J, Cloughesy TF, Fink K, Gilbert M, Chang S, Junck L, Schiff D, Lieberman F, Fine HA, Mehta M, Robins HI, DeAngelis LM, Groves MD, Puduvalli VK, Levin V, Conrad C, Maher EA, Aldape K, Hayes M, Letvak L, Egorin MJ, Capdeville R, Kaplan R, Murgo AJ, Stiles C, Prados MD: Phase I/II study of imatinib mesylate for recurrent malignant gliomas: North American Brain Tumor Consortium Study 99-08. Clin Cancer Res 2006, I 2:4899-907.

23. Giuliano $\mathrm{AE}, \mathrm{McC}$ all L, Beitsch $\mathrm{P}$, Whitworth $\mathrm{PW}$, Blumencranz $\mathrm{P}$, Leitch AM, Saha S, Hunt KK, Morrow M, Ballman K: Locoregional recurrence after sentinel lymph node dissection with or without axillary dissection in patients with sentinel lymph node metastases: the American College of Surgeons Oncology Group Z00 I I randomized trial. Ann Surg 2010, 252:426-32; discussion 432-3.

\section{FlOOOPrime}

\section{RECOMMENDED}

24. Morrow M, Jagsi R, Alderman AK, Griggs J], Hawley ST, Hamilton AS, Graff JJ, Katz SJ: Surgeon recommendations and receipt of mastectomy for treatment of breast cancer. JAMA 2009, 302: $|55|-6$.

25. McCahill LE, Single RM, Aiello Bowles EJ, Feigelson HS, James TA Barney $T$, Engel JM, Onitilo AA: Variability in reexcision following breast conservation surgery. JAMA 20I2, 307:467-75.

26. Moran MS, Schnitt SJ, Giuliano AE, Harris JR, Khan SA, Horton J, Klimberg S, Chavez-Macgregor M, Freedman G, Houssami N, Johnson PL, Morrow M: Society of Surgical Oncology-American Society for Radiation Oncology Consensus Guideline on Margins for Breast-Conserving Surgery With Whole-Breast Irradiation in Stages I and II Invasive Breast Cancer. J Clin Oncol 2014, 88:553-6.

\section{FIOOOPrime}

\section{RECOMMENDED}

27. Houssami N, Macaskill P, Marinovich ML, Morrow M: The association of surgical margins and local recurrence in women with earlystage invasive breast cancer treated with breast-conserving therapy: a meta-analysis. Ann Surg Oncol 2014, 2 I:7I7-30.

28. Early Breast Cancer Trialists' Collaborative Group (EBCTCG), Darby S, McGale P, Correa C, Taylor C, Arriagada R, Clarke M, Cutter D, Davies C, Ewertz M, Godwin J, Gray R, Pierce L, Whelan T, Wang Y, 
Peto R: Effect of radiotherapy after breast-conserving surgery on 10 -year recurrence and 15 -year breast cancer death: metaanalysis of individual patient data for 10,801 women in 17 randomised trials. Lancet 2011, 378:1707-16.

\section{FlOOOPrime}

29. Fisher B, Anderson S, Bryant J, Margolese RG, Deutsch M, Fisher ER, Jeong JH, Wolmark N: Twenty-year follow-up of a randomized trial comparing total mastectomy, lumpectomy, and lumpectomy plus irradiation for the treatment of invasive breast cancer. N Engl J Med 2002, 347:|233-4|.

30. Veronesi U, Cascinelli N, Mariani L, Greco M, Saccozzi R, Luini A, Aguilar M, Marubini E: Twenty-year follow-up of a randomized study comparing breast-conserving surgery with radical mastectomy for early breast cancer. N Engl J Med 2002, 347:1227-32.

31. Overgaard M, Hansen PS, Overgaard J, Rose C, Andersson M, Bach F, Kjaer M, Gadeberg CC, Mouridsen HT, Jensen MB, Zedeler K: Postoperative radiotherapy in high-risk premenopausal women with breast cancer who receive adjuvant chemotherapy. Danish Breast Cancer Cooperative Group 82b Trial. N Engl J Med 1997, 337:949-55.

\section{FlOOOPrime}

\section{RECOMMENDED}

32. Overgaard $M$, Jensen $M B$, Overgaard J, Hansen PS, Rose $C$, Andersson M, Kamby C, Kjaer M, Gadeberg CC, Rasmussen BB, Blichert-Toft M, Mouridsen HT: Postoperative radiotherapy in high-risk postmenopausal breast-cancer patients given adjuvant tamoxifen: Danish Breast Cancer Cooperative Group DBCG 82c randomised trial. Lancet 1999, 353:164|-8.

\section{FlOOOPrime} RECOMMENDED

33. Ragaz J, Olivotto IA, Spinelli JJ, Phillips N, Jackson SM, Wilson KS, Knowling MA, Coppin CM, Weir L, Gelmon K, Le N, Durand R, Coldman A], Manji M: Locoregional radiation therapy in patients with high-risk breast cancer receiving adjuvant chemotherapy: 20-year results of the British Columbia randomized trial. J Natl Cancer Inst 2005, 97: | |6-26.

\section{FlOOOPrime}

\section{RECOMMENDED}

34. Arvold ND, Taghian AG, Niemierko A, Abi Raad RF, Sreedhara M, Nguyen PL, Bellon JR, Wong JS, Smith BL, Harris JR: Age, breast cancer subtype approximation, and local recurrence after breast-conserving therapy. J Clin Oncol 20I I, 29:3885-9I.

35. Fisher B, Bryant J, Dignam JJ, Wickerham DL, Mamounas EP, Fisher ER, Margolese RG, Nesbitt L, Paik S, Pisansky TM, Wolmark N; National Surgical Adjuvant Breast and Bowel Project: Tamoxifen, radiation therapy, or both for prevention of ipsilateral breast tumor recurrence after lumpectomy in women with invasive breast cancers of one centimeter or less. J Clin Oncol 2002, 20:4I4I-9.

\section{FlOOOPrime}

\section{RECOMMENDED}

36. Fyles AW, McCready DR, Manchul LA, Trudeau ME, Merante $P$, Pintilie M, Weir LM, Olivotto IA: Tamoxifen with or without breast irradiation in women $\mathbf{5 0}$ years of age or older with early breast cancer. $N$ Engl J Med 2004, 35 I:963-70.

37. Hughes KS, Schnaper LA, Bellon JR, Cirrincione CT, Berry DA, McCormick B, Muss HB, Smith BL, Hudis CA, Winer EP, Wood WC: Lumpectomy plus tamoxifen with or without irradiation in women age 70 years or older with early breast cancer: longterm follow-up of CALGB 9343. J Clin Oncol 2013, 3 1:2382-7.

38. Potter R, Gnant M, Kwasny W, Tausch C, Handl-Zeller L, Pakisch B, Taucher S, Hammer J, Luschin-Ebengreuth G, Schmid M, Sedlmayer F, Stierer M, Reiner G, Kapp K, Hofbauer F, Rottenfusser A, Pöstlberger S, Haider K, Draxler W, Jakesz R; Austrian Breast and Colorectal Cancer Study Group: Lumpectomy plus tamoxifen or anastrozole with or without whole breast irradiation in women with favorable early breast cancer. Int J Radiat Oncol Biol Phys 2007, 68:334-40.

39. Winzer KJ, Sauerbrei W, Braun M, Liersch T, Dunst J, Guski H, Schumacher M; German Breast Cancer Study Group (GBSG): Radiation therapy and tamoxifen after breast-conserving surgery: updated results of a $2 \times 2$ randomised clinical trial in patients with low risk of recurrence. Eur J Cancer 2010, 46:95-10I.

40. Olivotto IA, Whelan TJ, Parpia S, Kim DH, Berrang T, Truong PT, Kong I, Cochrane B, Nichol A, Roy I, Germain I, Akra M, Reed M, Fyles A, Trotter T, Perera F, Beckham W, Levine MN, Julian JA: Interim cosmetic and toxicity results from RAPID: a randomized trial of accelerated partial breast irradiation using three-dimensional conformal external beam radiation therapy. J Clin Oncol 2013, 31:4038-45.

\section{FlOOOPrime
RECOMMENDED}

4I. Giuliano AE, McCall L, Beitsch P, Whitworth PW, Blumencranz P, Leitch AM, Saha S, Hunt KK, Morrow M, Ballman K: Locoregional recurrence after sentinel lymph node dissection with or without axillary dissection in patients with sentinel lymph node metastases: the American College of Surgeons Oncology Group Z00II randomized trial. Ann Surg 2010, 252:426-32; discussion 432-3.

42. Straver ME, Meijnen $P$, van Tienhoven G, van de Velde CJ, Mansel RE, Bogaerts J, Duez N, Cataliotti L, Klinkenbijl JH, Westenberg HA, van der Mijle H, Snoj M, Hurkmans C, Rutgers Ej: Sentinel node identification rate and nodal involvement in the EORTC 1098|-22023 AMAROS trial. Ann Surg Oncol 2010, 17:|854-6I.

43. Emiel J. Rutgers, Mila Donker, Marieke Evelien Straver, Philip Meijnen, Cornelis J. H. Van De Velde, Robert E. Mansel, Helen Westenberg, Lorenzo Orzalesi, Willem H. Bouma, Huub van der Mijle, Grard A. P. Nieuwenhuijzen, Sanne C. Veltkamp, Leen Slaets, Carlo G. M. Messina, Nicole J. Duez, Coen Hurkmans, Jan Bogaerts, Geertjan van Tienhoven; Radiotherapy or surgery of the axilla after a positive sentinel node in breast cancer patients: Final analysis of the EORTC AMAROS trial (1098I/22023) [abstract]. Presented at the American Society of Clinical Oncolgy Anuual Meeting: 3I May-4 June2013; Chicago, IL.

44. von Minckwitz G, Untch M, Blohmer JU, Costa SD, Eidtmann H, Fasching PA, Gerber B, Eiermann W, Hilfrich J, Huober J, Jackisch C, Kaufmann M, Konecny GE, Denkert C, Nekljudova V, Mehta K, Loibl S: Definition and impact of pathologic complete response on prognosis after neoadjuvant chemotherapy in various intrinsic breast cancer subtypes. I Clin Oncol 2012, 30:1796-804

45. Mamounas EP, Anderson SJ, Dignam JJ, Bear HD, Julian TB, Geyer CE Jr, Taghian A, Wickerham DL, Wolmark N: Predictors of locoregional recurrence after neoadjuvant chemotherapy: results from combined analysis of National Surgical Adjuvant Breast and Bowel Project B-I8 and B-27. J Clin Oncol 2012. 30:3960-6.

\section{FlOOOPrime
RECOMMENDED}

46. McGuire SE, Gonzalez-Angulo AM, Huang EH, Tucker SL, Kau SW, Yu TK, Strom EA, Oh JL Woodward WA, Tereffe W, Hunt KK, Kuerer HM, Sahin AA, Hortobagyi GN, Buchholz TA: Postmastectomy radiation improves the outcome of patients with locally advanced breast cancer who achieve a pathologic complete response to neoadjuvant chemotherapy. Int J Radiat Oncol Biol Phys 2007, 68:1004-9.

47. Baselga J, Cortes J, Kim SB, Im SA, Hegg R, Im YH, Roman L, Pedrini JL, Pienkowski T, Knott A, Clark E, Benyunes MC, Ross G, Swain SM; CLEOPATRA Study Group: Pertuzumab plus trastuzumab plus docetaxel for metastatic breast cancer. $N$ Engl J Med 2012, 366:109-19.

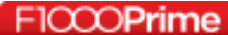

\section{RECOMMENDED}

48. Verma S, Miles D, Gianni L, Krop IE, Welslau M, Baselga J, Pegram M, Oh DY, Diéras V, Guardino E, Fang L, Lu MW, Olsen S, Blackwell K; 
EMILIA Study Group: Trastuzumab emtansine for HER2-positive advanced breast cancer. N Engl J Med 20I2, 367: I783-9I.

\section{FlOOOPrime}

RECOMMENDED

49. Baselga J, Campone M, Piccart M, Burris HA 3rd, Rugo HS, Sahmoud T, Noguchi S, Gnant M, Pritchard KI, Lebrun F, Beck JT, Ito Y, Yardley D,
Deleu I, Perez A, Bachelot T, Vittori L, Xu Z, Mukhopadhyay P, Lebwohl D, Hortobagyi GN: Everolimus in postmenopausal hormone-receptor-positive advanced breast cancer. $N$ Engl J Med 20I 2, 366:520-9.

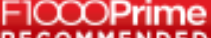

RECOMMENDED 